\title{
Implementation Strategies and Outcomes for Occupational Therapy in Adult Stroke Rehabilitation: A Scoping Review
}

\author{
J. Edward Murrell ( $\nabla$ ed21@uab.edu ) \\ UAB: University of Alabama at Birmingham https://orcid.org/0000-0002-4204-8075 \\ Janell L. Pisegna \\ The Ohio State University School of Health and Rehabilitation Sciences \\ Lisa A. Juckett \\ The Ohio State University School of Health and Rehabilitation Sciences
}

\section{Research}

Keywords: implementation strategies, implementation outcomes, occupational therapy, stroke rehabilitation

Posted Date: February 23rd, 2021

DOI: https://doi.org/10.21203/rs.3.rs-229354/v1

License: () (i) This work is licensed under a Creative Commons Attribution 4.0 International License. Read Full License

Version of Record: A version of this preprint was published at Implementation Science on December 1st, 2021. See the published version at https://doi.org/10.1186/s13012-021-01178-0. 


\section{Abstract}

Background

Every year, millions of people worldwide experience a stroke. Given the degree of physical, cognitive, visual, and behavioral impairments post-stroke, stroke survivors often encounter occupational therapy practitioners in the rehabilitation practice settings. Although evidence-based occupational therapy practices have been well-established in the stroke literature, it remains unclear what strategies have been used to promote these practices' effective implementation in the real-world context. The present review identifies these strategies and the extent to which researchers have measured implementation outcomes.

Methods

A scoping review protocol was developed to assess the breadth and depth of occupational therapy literature examining implementation strategies and outcomes in the stroke rehabilitation field. Four electronic databases and two peer-reviewed implementation science journals were searched to identify studies meeting inclusion criteria. Two reviewers applied the inclusion parameters and consulted with a third reviewer, as needed, to achieve consensus. The Expert Change guided synthesis of review findings for Implementing Change project and the Implementation Outcomes Framework.

Results

The initial search yielded 1219 studies, and 26 were included in the final review. A total of 48 out of 73 discrete implementation strategies were deployed in the included studies. The most used implementation strategies were "distribute educational materials," "assess for readiness and identify barriers and facilitators," and "conduct educational outreach visits." "Adoption" was the most frequently measured implementation outcome, while "cost" was not measured in any included studies. Eleven studies reported findings to support the effectiveness of their implementation strategy or strategies; eleven studies reported inconclusive findings, and four studies found that their strategies did not lead to improved implementation outcomes.

Conclusions

This scoping review identified occupational therapy literature examining implementation strategies and outcomes in the context of stroke rehabilitation. With the growth of the stroke survivor population, the occupational therapy profession must identify effective strategies that promote the uptake of evidence-based practices into routine stroke care. Occupational therapy researchers and practitioners are encouraged to collaborate to develop and deploy implementation strategies responsive to known implementation barriers and facilitators in the stroke rehabilitation setting.

\section{Contributions To The Literature}

a. Approximately $65 \%$ of the strategies described in the Expert Recommendations for Implementing Change (ERIC) taxonomy have been examined in the stroke rehabilitation literature. Adoption has been the most commonly-measured implementation outcome.

b. Implementation strategies most frequently deployed in stroke rehabilitation research included the distribution of educational materials and the assessment of readiness and barriers/facilitators.

c. It remains unclear which implementation strategies are most effective for improving implementation outcomes. Notably, only 12 of 26 studies included in this review were guided by an implementation theory, model, or framework, which may partially explain the variability in study findings.

\section{Background}

Every year millions of people worldwide experience a stroke $(1,2)$. In 2016, there were over 80 million prevalent and over 13 million new cases of stroke (3). At high risk for stroke are persons who are 65 and older, practice unhealthy behaviors (smoking, poor diet, and physical inactivity), have metabolic risks (high blood pressure, high glucose, decreased kidney function, obesity, and high cholesterol), and represent lower socioeconomic groups $(1,4,5)$. With the rapid growth of the aging population, stroke incidence is expected to rise dramatically in the coming years, contributing to a shift in increased global disease burden due to more years lived with disability (YLD) from noncommunicable diseases (6-9). Stroke is one of the leading causes of long-term disability worldwide, and stroke survivors often face extensive challenges that result in self-care dependency, mobility impairments, underemployment, and cognitive deficits (1, 10). Frequently, stroke survivors are admitted to stroke rehabilitation settings, such as outpatient care centers, skilled nursing facilities, and home health agencies, and encounter occupational therapy (OT) practitioners to address these physical, cognitive, and psychosocial challenges (10-13). Considered allied health professionals, OT practitioners across the stroke rehabilitation continuum are expected to implement a person-centered care plan using evidence-based assessments and interventions intended to maximize stroke survivors' independence in daily activities and routines (e.g., dressing, bathing, mobility). Furthermore, healthcare consumers, such as stroke survivors, expect practitioners to utilize evidence-based practice (EBP) to provide the highest quality, costefficient patient services.

The benefits of OT in stroke rehabilitation have been well-established for decades (14). For instance, evidence-based OT interventions can lead to improved upper extremity movement $(15,16)$, enhanced cognitive performance (17), and increased safety with mobility (18). However, as with several allied health professions, OT practitioners can experience complex barriers when implementing evidence-based care into routine practice (19-21). Specific to stroke rehabilitation, Juckett et al. (22) identified several barriers that limited OT practitioners' uptake of evidence and categorized these barriers according to the Consolidated Framework for Implementation Research (CFIR) (23). Notable barriers to evidence use were attributed to challenges adapting evidence-based programs and interventions to meet patients' needs (i.e., adaptability), a lack of equipment and personnel (i.e., available resources), and insufficient practitioner knowledge on using new interventions (i.e., knowledge and beliefs). Although identifying these barriers is a necessary precursor to optimizing evidence implementation, Juckett et al. (22) also emphasized the urgent need for OT researchers and practitioners to identify implementation strategies that

Page 2/21 
effectively facilitate the uptake of evidence in stroke rehabilitation. Jones et al. (24) examined the literature regarding implementation strategies used in the rehabilitation profession - occupational therapy, physical therapy, and speech-language pathology. While they found some encouraging findings, they could not provide definitive recommendations due to the included studies' heterogeneity. However, the authors did suggest that the complexity of implementing interventions will require various strategies specific to each rehabilitation discipline (24).

Implementation strategies are broadly defined as methods to enhance the adoption, uptake, and sustainment of evidence-based interventions, programs, or innovations $(25,26)$. Over the past decade, these strategies have been compiled into taxonomies to facilitate researchers' and practitioners' ability to conceptualize implementation strategies and apply them into practice. For instance, the Expert Recommendations for Implementing Change (ERIC) project (27) describes 73 implementation strategies that can be leveraged to optimize the uptake of evidence into routine care. Such implementation strategies may be considered effective if they lead to improvements in implementation outcomes. Proctor et al. (28) defined the following eight outcomes in their Implementation Outcomes Framework (IOF) that are often perceived to be the "gold standard" outcomes in implementation research: acceptability, adoption, appropriateness, cost, feasibility, fidelity, penetration (e.g., reach), and sustainability.

Although implementation research has seen significant progress in recent years, there is scarce evidence that examines the effectiveness of implementation strategies in the allied health professions, such as occupational therapy (24). Implementation strategies such as educational meetings, audit and feedback techniques, and the use of clinical reminders hold promise for increasing the use of evidence by allied health professionals (24); however, minimal guidance exists for the application of these strategies in stroke rehabilitation, especially in the context of occupational therapy. This knowledge gap is particularly concerning given the heightened interest from insurance payers in evidence-based interventions and associated patient outcomes (29). As a recent example, the Centers for Medicare and Medicaid Services (CMS) has begun overhauling reimbursement for rehabilitation services by focusing less on the number of patients treated and more on the value of services delivered. In other words, rehabilitation settings are reimbursed based on the quality of services implemented (as measured by improvements in patient outcomes) rather than the quantity of services provided. The increased attention on patient outcomes from the policy level (i.e., CMS) warrants the immediate need for OT practitioners to implement the highest quality of interventions with patients, such as stroke survivors, to improve stroke survivor outcomes and ensure that rehabilitation stakeholders are adequately reimbursed (30, 31).

As OT practitioners aim to implement high-quality, evidence-based interventions to stroke survivors, the OT profession must have a clear understanding of the strategies that have been used to support evidence implementation. Barriers to evidence implementation among OT practitioners have been well-established $(19,22)$. Attention must now shift towards evaluating the implementation strategies that lead to improved implementation outcomes. Therefore, the purpose of this scoping review is to synthesize occupational therapy research that has examined implementation strategies in stroke rehabilitation. Guided by the ERIC discrete implementation strategy compilation (27) and Proctor et al.'s (28) taxonomy of implementation outcomes, this scoping review was designed to answer the following two research questions:

1. What implementation strategies have occupational therapy researchers used to support the uptake of evidence-based interventions and assessments in stroke rehabilitation?

2. What outcomes have been measured to determine the effectiveness of implementation strategies in stroke rehabilitation?

Addressing these questions will point OT practitioners towards strategies that may support evidence implementation in their stroke rehabilitation settings. Moreover, this review will also inform the work of OT researchers who seek to test multifaceted implementation strategies designed to facilitate the uptake of interventions, programs, and assessments across the stroke rehabilitation continuum.

\section{Methods}

The scoping review methodology was guided by (a) Arksey and O'Malley's scoping review framework (32) and (b) the Preferred Reporting Items for Systematic Reviews and Meta-Analyses Scoping Review (PRISMA-ScR) reporting recommendations (33). The review team developed an initial study protocol (unregistered; available upon request) to address the review questions and identify the breadth of literature examining implementation strategies and outcomes in stroke rehabilitation. The first author conducted preliminary searches to assess the available literature, allowing the team to revise the search strategy and search terms, consistent with scoping reviews' iterative nature. A detailed description of the search strategy can be found in Appendix A.

\section{Eligibility Criteria}

Studies were eligible for inclusion in the review if they (a) were published between Jan 2000 - Jan 2020, (b) examined the implementation of interventions or assessments, (c) had a target population of adult (19 years and older) stroke survivors, (d) included occupational therapy practitioners, and (e) were relevant to the rehabilitation setting. Rehabilitation was defined as acute care hospitals and post-acute care home health agencies, skilled nursing facilities, long-term acute care hospitals, hospice, inpatient rehabilitation facilities and units, and outpatient centers. Studies that only reported on intervention effectiveness (not implementation strategy effectiveness) or assessment psychometrics were excluded. Studies that were not available in English examined pediatric patients, were published as a review or conceptual article and failed to include occupational therapy practitioners as study participants were also excluded.

\section{Information source \& search strategy}

The following four electronic databases were accessed to identify relevant studies in the health and mental health fields: PubMed, CINAHL, Scopus, and PsychINFO. Implementation Science and Implementation Science Communications were also hand-searched. These are the premier peer-reviewed journals in dissemination and implementation research. Given the diverse terminology used to describe implementation strategies in the stroke rehabilitation field, an 
extensive list of terms to conduct the comprehensive search was used. The most recent search was conducted in May 2020. Sample search term combinations included "knowledge translation"[All Fields] OR "implement*"[All Fields]) AND "occupational therap*"[All Fields] AND "stroke"[MeSH Terms] OR "stroke" (See Appendix for full terminology list and a database search sample). All studies identified through the search strategy were uploaded into Covidence in preparation for study selection.

\section{Selection Process}

Beginning with the study title/abstract screening phase, the first and second authors applied the inclusion and exclusion criteria to all studies that were identified in the initial search. When authors disagreed during title/abstract screening, the third author decided on studies that should advance to the full-text review phase. All authors reviewed a random $15 \%$ of the full-text articles in the full-text phase to decide on study inclusion and evaluate consistency in how each author applied the inclusion/exclusion criteria. The authors achieved 100\% agreement and proceeded with screening each full-text article individually.

\section{Data charting-Guiding frameworks}

Implementation strategies. Historically, the terminology and definitions used to describe implementation strategies have been inconsistent and lacking in details $(27,34,35)$. As part of the ERIC project, Powell and other experts compiled a list of 73 discrete implementation strategy terms and definitions that could be used as a tool for evaluating published literature $(27,35)$. The researchers also suggested that the refined compilation could be used as a common language to guide future implementation research and practice (27). Additionally, as part of the ERIC project, the expert panel examined the relationships among the discrete implementation strategies to determine any themes (34). Figure 1 shows the resulting nine clusters of implementation strategies: use evaluative and iterative strategies, provide interactive assistance, adapt and tailor to the context, develop stakeholder interrelationships, train and educate stakeholders, support clinicians, engage consumers, utilize financial strategies, and change infrastructure (34). The nine clusters were used to identify trends of implementation strategy utilization and synthesize extracted data to address this scoping review's primary research question and objective.

Implementation outcomes. In the IOF, Proctor et al. defined implementation outcomes as "the effects of deliberate and purposive actions to implement new treatments, practices, and services (28)." The secondary research question aimed to examine studies measuring the effectiveness of the implementation strategies; therefore, Proctor et al.'s (28) taxonomy of implementation outcomes was used to guide data analysis and promote common vocabulary in implementation research. These eight implementation outcomes (acceptability, adoption, appropriateness, cost, feasibility, fidelity, penetration, and sustainability) serve as key indicators of implementation success or failure.

\section{Data charting-Extraction process}

An adapted version of Arksey and O'Malley's data charting form was created to extract variables of interest from each study that met the inclusion criteria. In the data extraction phase, all authors extracted data from another random $15 \%$ of included studies to pilot test the charting form and confirm the final variables to be extracted. Authors met on a bi-weekly basis to share progress on independent data extraction and compare the detail of data extracted across authors. Variables were extracted that represented study design, population, setting, guiding frameworks, and the description of the intervention/assessment being implemented; however, the review's primary aim was extracting information relative to implementation strategies and associated implementation outcomes.

To do this, a two-step process to extract data on implementation strategies and outcomes was used. In Step 1, each review team member charted the information and specific terminology used to describe strategies or outcomes as written by each study's original authors. In Step 2, a directed content analysis approach to map this charted information and terminology to the ERIC taxonomy (27) and the IOF was used (28). For instance, an implementation strategy that was described as "holding in-services with clinicians" in an article was transformed to "conducting educational meetings," and outcomes that were initially described as "adherence" were converted to "fidelity." The selection of these two frameworks to guide the data charting process was based on the need to use uniform nomenclature when describing implementation strategies and their associated implementation outcomes. The two-step charting process also allowed the review team to discuss the accuracy with which ERIC and IOF terms matched the descriptions of implementation strategies and outcomes as described by each study's authors.

\section{Synthesis Process}

The data were extracted from the articles and charted in tabular form. After the reviewers had inputted all data, one reviewer checked for errors making any necessary changes. Once complete, all authors reviewed and verified the accuracy of the data extracted and reached $100 \%$ agreement regarding the data's accuracy. One author organized the raw data material and converted it into pivot tables and charts to synthesize data needed to address this scoping review's research questions and objectives. The results were later converted into tabular form to illustrate better the relationships between concepts, questions, and objectives. All data analysis and synthesis were conducted using Microsoft Excel.

\section{Results \\ Search results}

Electronic bibliographic database searches yielded 1219 publications, of which 49 were considered potentially relevant and retrieved in full text for further review. Twenty-three publications were excluded because the studies did not examine implementation strategies or include implementation outcomes. Others

Page $4 / 21$ 
had the wrong population, article type, or rehabilitation discipline. Ultimately, 26 studies were included, as shown by the selection process illustrated in Figure 2. Twenty-six relevant publications were identified, describing 48 out of 73 discrete implementation strategies defined by Powell et al. (27). The publications identified also describe and include implementation outcomes as defined by Procter et al. (28).

\section{Study Inclusion}

The full spectrum of studies examining implementation strategies and outcomes was published between 2005 and 2020 and all within the last ten years except one. Table 1 demonstrates that the included studies were conducted throughout the Americas, Europe, Australia, and Africa. Several research designs were noted among the studies, with most research designs being longitudinal, as demonstrated in Table 1 . All 26 studies included occupational therapy practitioners (consisting of occupational therapists and occupational therapy assistants) implementing interventions and assessments targeting adults, 19 years old and older, in stroke rehabilitation.

Half of the studies only implemented interventions, while the remaining studies implemented some combination of assessments (screenings, protocols, guideways, and pathways) and interventions. The studies were conducted with occupational therapy practitioners practicing in several healthcare settings, including acute care, inpatient rehabilitation, skilled nursing, outpatient, community, and long-term care. However, three of the studies implemented EBP aimed at occupational therapists working in any healthcare setting and was provided either at an off-site location (36) or non-physical (37) or virtual (38) environment. None of the studies included EBP being implemented in the long-term acute care hospital or hospice healthcare settings to the authors' knowledge.

\section{Synthesis Summary}

Primary research question: The first question of this scoping review addressed what implementation strategies occupational therapy researchers have used to support the uptake of interventions and assessments in stroke rehabilitation. The included studies collectively used 48 of the 73 discrete implementation strategies in the ERIC project compilation, as shown in Figure 3. The two most used discrete strategies were [31] Distribute educational materials (36, 38-47) and [4] Assess for readiness \& identify barriers \& facilitators $(34,38,40,42-48,54)$, which were implemented each by 11 studies as shown in Figure 3. Regarding the latter strategy, only two of the 11 studies $(45,46)$ assessed for readiness and identified barriers \& facilitators. The remaining nine studies only identified barriers \& facilitators. The second most utilized discrete strategy was [16] Conduct educational outreach visits implemented by ten studies (36, 39, $41,43,45,46,48-51)$. Other frequently used discrete strategies include [19] Conduct ongoing training, [5] Audit \& provide feedback, and [29] Develop educational materials, each of which was implemented in eight of the studies.

None of the studies implemented discrete strategies across all the implementation strategy clusters. Table 1 shows that one study (44) did utilize at least one strategy addressing seven out of the nine clusters and two studies $(51,52)$ did the same with six out of nine clusters. Twenty-three out of 26 studies implemented discrete strategies within the train and educate stakeholders cluster. The discrete implementation strategy utilized the most within this cluster was [31] Distribute educational materials. The studies also frequently utilized discrete implementation strategies from the following two clusters: use evaluative and iterative strategies and develop stakeholder interrelationships. Seventeen studies implemented strategies in the evaluative and interactive strategies cluster (40, 42, 44-49, 51-59), with [4] Assess for readiness \& identify barriers \& facilitators being implemented the most within this cluster. Discrete strategies from the develop stakeholder relationships cluster were used in 12 studies $(37,39,40,43,44,46,49,50,52,56,60,61)$, with [35] Identify \& prepare champions being implemented the most with 7 studies $(39,43,44,46,49,56,61)$.

The same strategies were primarily implemented across the different studies in the following three clusters: provide interactive assistance, adapt and tailor to context, and support clinicians. In the provide interactive assistance cluster, four out of eight studies used [33] Facilitation and three out of eight studies used [54] Provide local technical assistance. Six studies utilized strategies from the adapt and tailor to context cluster. The discrete strategy [51] Promote adaptability was used in four of six studies, and three of the six studies implemented [63] Tailor strategies. Among the eight studies that implemented discrete strategies categorized in the support clinicians cluster, only two different discrete strategies were used. The strategy, [58] Remind clinicians, was almost exclusively used, with seven out of eight studies only implementing this strategy. The one remaining study utilized the discrete strategy [30] Develop resource sharing agreements.

The three implementation clusters from which the studies implemented the least number of discrete strategies were the clusters utilize financial strategies, change infrastructure, and engage consumers. Only one study, (44), implemented strategies from utilize financial strategies, two studies (44, 51) utilized a strategy from change infrastructure, and two studies $(51,52)$ used at least one strategy in the engage consumers cluster as shown in Table 1 . The two discrete implementation strategies used within the cluster utilize financial strategies were [2] Alter incentive/allowance structure and [34] Fund \& contract for the clinical innovation. The two discrete strategies implemented from the cluster, change infrastructure, were [44] Mandate change and [11] Change physical structure \& equipment. The same occurs in the engage consumers cluster with the implementation of two discrete strategies - [41] Involve patients/consumers \& family members and [50] Prepare patients/consumers to be active participants.

Secondary research question. This scoping review's second question addressed what outcomes have been measured to determine stroke rehabilitation implementation strategies' effectiveness. The implementation outcome measured the most was adoption, which was evaluated in 21 out of 26 studies (36-38, 40-46, 48-50, 52, 54-56, 58-61). The second implementation outcome most frequently measured was fidelity with ten studies (41, 42, 47, 50, 51, 53, 55, 57, 58, $60)$, as shown in Table 1. Fifteen studies measured two implementation outcomes, and eight studies measured one outcome. Among those eight studies, either adoption or fidelity was the only outcome measured. Three of the 26 studies measured more than two outcomes, with two studies (44, 45) measuring three and the remaining study (37) measuring four. While none of the studies measured the outcome of cost, the least measured outcomes were penetration and sustainability. Table 1 shows that one study (44) measured both outcomes. 
Influence of implementation strategies. The findings from studies examining the effect of implementation strategies on implementation outcomes were generally mixed. While 11 studies deployed strategies that led to improved implementation outcomes, 13 studies led to inconclusive results. For instance, McEwen et al. (43) developed a multifaceted implementation strategy that involved conducting educational meetings, providing ongoing education, appointing evidence champions, distributing educational materials, and reminding clinicians to implement evidence in practice. These strategies led to increased adoption of their target EBP, the Cognitive Orientation to daily Occupational Performance (CO-OP) treatment approach, suggesting the multifaceted strategy was effective. Alternatively, Salbach and colleagues (46) examined the impact of an implementation strategy consisting of educational meetings, evidence champions, educational materials, local funding, and implementation barrier identification that pertained to stroke guideline adoption. However, these strategies only led to the increased adoption of two out of 18 recommendations described in the stroke guidelines.

Levac et al. (61) also deployed a combination of educational meetings, dynamic training, reminders, and expert consultation to increase the use of virtual reality therapy with stroke survivors, yet found these combined strategies did not lead to an increase in virtual reality adoption among practitioners serving stroke survivors.

Use of theories, models, and frameworks. Notably, of the 26 included articles, 12 articles explicitly stated using a theory, model, or framework (TMF) guiding the intervention utilized in the article (findings summarized in Table 2). The most common supporting TMF employed among the articles was the Knowledgeto-Action framework $(n=5)$. Other TMFs included class theories such as the Behavior Change Wheel $(n=3)$ and Theory of Planned Behavior $(n=1)$. Determinant frameworks represented included the Consolidated Framework for Implementation Research (CFIR) $(n=1)$, the Theoretical Domains Framework ( $n=1)$, and the integrated-Promoting Action on Research Implementation in Health Services (iPARIHS) framework ( $n=1)$. Two studies applied the Normalization Process Theory. No implementation evaluation frameworks were utilized (such as Reach, Efficacy, Adoption, Implementation, Maintenance (RE-AIM) or Implementation Outcomes Framework) or implementation process models (such as Dynamic Sustainability/Adaptation, Practical, Robust Implementation and Sustainability Model (PRISM), Exploration, Adoption/Preparation, Implementation, Sustainment (EPIS), or Quality Implementation). A select number of studies

described the components of their implementation strategies in accordance with reporting guidelines, including the Template for Intervention Description and Replication (TIDieR) checklist ( $n=2$ ), the Standards for Quality Improvement Reporting Excellence (SQUIRE) ( $=1$ ), and Standards for Reporting Implementation studies (StaRI) $(n=1)$, but did not explicitly mention the use of an implementation framework to guide the intervention.

\section{Discussion}

This scoping review is one of the first to examine implementation strategy use and implementation outcome measurement in stroke rehabilitation in the context of occupational therapy. Given that implementation science is still nascent in occupational therapy, this review's purpose was to assess the breadth of implementation strategies and outcomes that have been evaluated in stroke rehabilitation and point to strategies that hold promise for facilitating the update of evidence into occupational therapy practice.

This review corroborates other reviews in the rehabilitation field, which have found the implementation strategies' effectiveness as mixed. However, one encouraging finding from the present review was the frequent use of the following implementation strategy: [4]assess for readiness and identify barriers and facilitators. The assessment of barriers and facilitators is a central precursor to selecting implementation strategies that effectively facilitate the use of evidence into practice (62). Implementation strategies that are not responsive to these barriers and facilitators frequently fail to produce sufficient and sustainable practice change $(62,63)$.

Although identifying implementation barriers and facilitators is of paramount importance in implementation studies, the processes researchers use to select relevant implementation strategies based on these barriers and facilitators are often unclear. Vratsistas-Curto et al. (47), for instance, assessed determinants of implementation at the start of their study and mapped determinants to the Theoretical Domains Framework and Behavior Change Wheel to inform implementation strategy selection. This use of TMFs can strengthen the rigor of implementation strategy selection and elevate strategy effectiveness. However, not all implementation studies are informed by underlying TMFs, calling into question the rationale behind why specific strategies are deployed in certain contexts. Going forward, as the fields of stroke rehabilitation and occupational therapy grow their interest in implementation, researchers must be transparent when explaining the process and justification of their implementation strategy selection. Without this transparency, occupational therapy stakeholders and other rehabilitation professionals may continue to deploy implementation strategies without systematically matching them to identified barriers and facilitators. Waltz et al. (62) gathered expert opinion data to develop a tool matching implementation barriers/facilitators to implementation strategies to assist in the process of strategy selection. The tool draws language from the Consolidated Framework for Implementation Research (CFIR) (23) and matches identified barriers/facilitators to the ERIC taxonomy of implementation strategies. Using the CFIR-ERIC matching tool may be a viable option for occupational therapy researchers who understand determinants of evidence implementation but require guidance when selecting relevant implementation strategies.

The other commonly examined implementation strategy identified in this review involved the use of educational meetings and materials. Eleven studies used one or more of these educational techniques to facilitate the implementation of evidence into practice. However, in the context of these educational techniques, all studies examining educational strategies failed to specify their implementation strategies as recommended by standard reporting guidelines (26). Proctor et al. (26) provided recommendations for how implementation strategies should be specified to optimize strategy replication. These recommendations suggest three different criteria (naming, defining, specifying) that should be described in all studies that test implementation strategies. Perhaps this lack of strategy specification can be attributed to the disciplinary divide in implementation nomenclature. Included studies often examined "knowledge translation interventions" or "knowledge translation strategies" (i.e., (61), (44)), and no studies referenced the ERIC taxonomy or IOF. Across the rehabilitation field, the term "knowledge translation" is commonly used as a synonym for moving research into practice and is a term that has been widely accepted in the rehabilitation field since $2000(24,64,65)$. While international rehabilitation leaders have articulated distinctions between "knowledge 
translation" and "implementation science," there is still tremendous work to be done in disseminating these distinctions to the broader rehabilitation audience $(64,65)$.

One surprising finding from this review was the variation with which studies were guided by implementation TMFs. Less than half of the studies $(n=12)$ integrated influences from TMFs drawn from the implementation literature. The Knowledge-to-Action framework was applied in five studies, followed by the Behavior Change Wheel and Normalization Process Theory represented in three and two studies, respectively. The lack of TMF application may also explain some of the variability in implementation strategy effectiveness. Interestingly, all 12 studies with TMF underpinnings found either mixed or beneficial outcomes as a result of their implementation strategies

Conversely, the three studies that found no effect of their strategies on implementation outcomes were not informed by any implementation TMF. While this subset of studies is too small to draw definitive conclusions, the importance of using TMFs to guide implementation studies has been well-established and endorsed by leading implementation scientists $(66,67)$. Despite their recognized importance, TMFs are often applied haphazardly in implementation projects (68). Birken et al. have begun to develop recommendations for selecting TMFs with examples of these recommendations, including assessing empirical support, considerations of applicability, and identifying the explanatory power of potential TMFs. The same recommendations may be useful to occupational therapy researchers in stroke rehabilitation who are new to the application of TMFs in implementation.

\section{Limitations}

While the present scoping review adds novel contributions to the implementation science field, stroke rehabilitation, and occupational therapy, it is not without limitations. First, scoping review methodologies have been critiqued for not requiring critical appraisals and bias assessments of included articles (69, 70). Given that this review's focus was to assess the breadth of implementation strategies and outcomes measured in a field (e.g., occupational therapy) newer to implementation science, critical appraisals and bias assessments have been deemed "not applicable" according to PRISMA-ScR reporting guidelines. Second, after training and consensus agreement, the study team independently extracted data from studies that pertained to implementation strategies and implementation outcomes. However, most studies did not define strategies and outcomes using the two guiding frameworks: the ERIC taxonomy and the Implementation Outcomes Framework. While this does serve as a limitation, it also points to the importance of specifying implementation strategies so that researchers and practitioners can replicate effective strategies, even when implementation nomenclature is not consistently used across fields. Lastly, the search was restricted to studies that included occupational therapy as the primary provider of interest. Thus, most of the studies deployed implementation strategies at the provider-level. The authors recognize that the effective implementation of best practices often requires organization- and system-level changes; therefore, the findings do not represent strategies and outcomes applicable to stroke rehabilitation clinics and the more extensive healthcare system.

\section{Conclusion}

This scoping review revealed the occupational therapy profession's use of implementation strategies and measurement of implementation outcomes in stroke rehabilitation. The profession has successfully created a small body of implementation science literature; however, occupational therapy researchers and practitioners must continue to develop and test implementation strategies to move evidence into practice. Advancements in this area of implementation research will enable occupational therapy stakeholders to deploy strategies that effectively increase evidence-based care implementation to the stroke survivor population.

Moreover, while the occupational therapy profession has made progress in adopting implementation science methodologies, researchers are encouraged to be more deliberate in selecting, using, and evaluating implementation strategies, outcomes, and frameworks. In particular, occupational therapy researchers must increase efforts to find effective implementation strategies for overcoming barriers faced in clinical settings. Failing to do so will continue to inhibit OT practitioners' ability to provide patients with high quality, cost-effective care in stroke rehabilitation.

\section{Abbreviations}

YLD: years lived with disability; OT: occupational therapy; CFIR: Consolidated Framework for Implementation Research; ERIC: Expert Recommendations for Implementing Change; IOF: Implementation Outcomes Framework; CMS: Centers of Medicare and Medicaid Services; PRISMA-ScR: Preferred Reporting Items for Systematic Reviews and Meta-Analyses Scoping Review; CO-OP: Cognitive Orientation to daily Occupational Performance; TMF: Theory, Model, or Framework; RE-AIM: Reach, Efficacy, Adoption, Implementation, and Maintenance; PRISM: Practical, Robust Implementation and Sustainability Model; iPARIHS: integrated-Promoting Action on Research Implementation in Health Services; EPIS: Exploration, Adoption/Preparation, Implementation, Sustainment; TIDieR: Template for Intervention Description and Replication; SQUIRE: Standards for Quality Improvement Reporting Excellence; STaRI: Standards for Reporting Implementation studies; JBI: Joanna Briggs Institute

\section{Declarations}

\section{Ethics approval and consent to participate}

Not applicable.

\section{Consent for publication}


Not applicable.

\section{Availability of data and materials}

All data analyzed in this review are available in the included published articles.

\section{Competing interests}

The authors declare that they have no competing interests.

\section{Funding}

No funding was received.

Authors' contributions

EM conceptualized the purpose of this scoping review. EM and LJ developed a research protocol informed by seminal scoping review and implementation science frameworks. All authors carried out all aspects of data collection and data analysis. EM and LJ wrote the first draft of the manuscript, and revisions were made together with JP. All authors approved the final version.

\section{Acknowledgments}

The authors thank reference librarian Megan Bell for support in the search process. The authors are also grateful for valuable comments on earlier proposal ideas: Larry R. Hearld, Gavin R. Jenkins, Hon Yuen, and Gregory Orewa.

\section{Authors' information}

${ }^{1} \mathrm{~J}$. Edward Murrell, MOT, OTR/L is a Ph.D. student and graduate research assistant, Health Services Administration Program, Department of Health Services Administration, School of Health Professions, The University of Alabama at Birmingham, Birmingham, Alabama, United States; Email: ed21@uab.edu.

${ }^{2}$ Janell L. Pisegna, MOT, OTR/L, CSRS, is a Ph.D. candidate, Division of Medical Dietetics and Health Sciences, School of Health and Rehabilitation Sciences, College of Medicine, The Ohio State University, Columbus, Ohio, United States; Email: pisegna.3@osu.edu

${ }^{3}$ Lisa A. Juckett, Ph.D., OTR/L, CHT is Instructor, Division of Occupational Therapy, School of Health and Rehabilitation Sciences, The Ohio State University, Columbus, Ohio, United States; Email: lisa.juckett@osumc.edu.

\section{References}

1. Virani SS, Alonso A, Benjamin EJ, Bittencourt MS, Callaway CW, Carson AP, et al. Heart Disease and Stroke Statistics-2020 Update: A Report From the American Heart Association. Circulation. 2020;141(9).

2. Kim J, Thayabaranathan T, Donnan GA, Howard G, Howard VJ, Rothwell PM, et al. Global Stroke Statistics 2019. International Journal of Stroke. 2020;15(8):819-38.

3. Johnson CO, Nguyen M, Roth GA, Nichols E, Alam T, Abate D, et al. Global, regional, and national burden of stroke, 1990-2016: a systematic analysis for the Global Burden of Disease Study 2016. The Lancet Neurology. 2019;18(5):439-58.

4. World Health Organization. Global atlas on cardiovascular disease prevention and control: World Health Organization; 2011 [Available from: https://www.who.int/cardiovascular_diseases/publications/atlas_cvd/en/.

5. World Stroke Organization. Global stroke fact sheet 2019 [Available from: https://www.worldstroke.org/assets/downloads/WSO_Global_Stroke_Fact_Sheet.pdf.

6. Gagliardi AR, Armstrong MJ, Bernhardsson S, Fleuren M, Pardo-Hernandez H, Vernooij RWM, et al. The Clinician Guideline Determinants Questionnaire was developed and validated to support tailored implementation planning. Journal of Clinical Epidemiology. 2019;113:129-36.

7. Vos T, Lim SS, Abbafati C, Abbas KM, Abbasi M, Abbasifard M, et al. Global burden of 369 diseases and injuries in 204 countries and territories, $1990-$ 2019: a systematic analysis for the Global Burden of Disease Study 2019. The Lancet. 2020;396(10258):1204-22.

8. Benjamin EJ, Virani SS, Callaway CW, Chamberlain AM, Chang AR, Cheng S, et al. Heart Disease and Stroke Statistics-2018 Update: A Report From the American Heart Association. Circulation. 2018;137(12):e67-e492.

9. Gorelick PB. The global burden of stroke: persistent and disabling. The Lancet Neurology. 2019;18(5):417-8.

10. Nilsen D, Geller D. The Role of Occupational Therapy in Stroke Rehabilitation [fact sheet]: American Occupational Therapy Association; 2015 [Available from: https://www.aota.org/-/media/Corporate/Files/AboutOT/Professionals/WhatlsOT/RDP/Facts/Stroke-Rehab-fact-sheet.pdf.

11. National Institute of Neurological Disorders and Stroke. Post-Stroke fact sheet [NIH Publication 20-NS-4846]. 2020. 
12. World Health Organization. Access to rehabilitation in primary health care: An ongoing challenge [WHO/HIS/SDS/2018.40]. Geneva: World Health Organization; 2018. Contract No.: CC BY-NC-SA 3.0 IGO.

13. Occupational Therapy Practice Framework: Domain and Process-Fourth Edition. American Journal of Occupational Therapy. 2020;74(Supplement_2):7412410010p1-p87.

14. Govender P, Kalra L. Benefits of occupational therapy in stroke rehabilitation. Expert Review of Neurotherapeutics. 2007;7:1013+.

15. Hatem SM, Saussez G, Della Faille M, Prist V, Zhang X, Dispa D, et al. Rehabilitation of Motor Function after Stroke: A Multiple Systematic Review Focused on Techniques to Stimulate Upper Extremity Recovery. Frontiers in Human Neuroscience. 2016.

16. Jolliffe L, Lannin NA, Cadilhac DA, Hoffmann T. Systematic review of clinical practice guidelines to identify recommendations for rehabilitation after stroke and other acquired brain injuries. BMJ Open. 2018;8(2):e018791.

17. Gillen G, Nilsen DM, Attridge J, Banakos E, Morgan M, Winterbottom L, et al. Effectiveness of Interventions to Improve Occupational Performance of People With Cognitive Impairments After Stroke: An Evidence-Based Review. American Journal of Occupational Therapy. 2014;69(1):6901180040p1-p9.

18. Wolf TJ, Chuh A, Floyd T, Mclnnis K, Williams E. Effectiveness of occupation-based interventions to improve areas of occupation and social participation after stroke: an evidence-based review. Am J Occup Ther. 2015;69(1):6901180060p1-11.

19. Samuelsson K, Wressle E. Turning evidence into practice: Barriers to research use among occupational therapists. British Journal of Occupational Therapy. 2015;78(3):175-81.

20. Institute of Medicine (US) Committee on Quality of Health Care in America. Crossing the Quality Chasm: A New Health System for the 21st Century. Washington, DC: The National Academies Press; 2001. 360 p.

21. Gustafsson L, Molineux M, Bennett S. Contemporary occupational therapy practice: The challenges of being evidence based and philosophically congruent. Australian Occupational Therapy Journal. 2014;61(2):121-3.

22. Juckett LA, Wengerd LR, Faieta J, Griffin CE. Evidence-Based Practice Implementation in Stroke Rehabilitation: A Scoping Review of Barriers and Facilitators. Am J Occup Ther. 2020;74(1):7401205050p1-p14.

23. Damschroder LJ, Aron DC, Keith RE, Kirsh SR, Alexander JA, Lowery JC. Fostering implementation of health services research findings into practice: a consolidated framework for advancing implementation science. Implementation Science. 2009;4(1):50.

24. Jones CA, Roop SC, Pohar SL, Albrecht L, Scott SD. Translating knowledge in rehabilitation: systematic review. Phys Ther. 2015;95(4):663-77.

25. Bauer MS, Damschroder L, Hagedorn H, Smith J, Kilbourne AM. An introduction to implementation science for the non-specialist. BMC Psychology. 2015;3(1):32.

26. Proctor EK, Powell BJ, McMillen JC. Implementation strategies: recommendations for specifying and reporting. Implementation Science. 2013;8(1):139.

27. Powell BJ, Waltz TJ, Chinman MJ, Damschroder LJ, Smith JL, Matthieu MM, et al. A refined compilation of implementation strategies: results from the Expert Recommendations for Implementing Change (ERIC) project. Implementation Science. 2015;10(1):21.

28. Proctor E, Silmere H, Raghavan R, Hovmand P, Aarons G, Bunger A, et al. Outcomes for Implementation Research: Conceptual Distinctions, Measurement Challenges, and Research Agenda. Administration and Policy in Mental Health and Mental Health Services Research. 2011;38(2):65-76.

29. Chambers JD, Chenoweth M, Cangelosi MJ, Pyo J, Cohen JT, Neumann PJ. Medicare Is Scrutinizing Evidence More Tightly For National Coverage Determinations. Health Affairs. 2015;34(2):253-60.

30. Centers of Medicare \& Medicaid Services. Overview of the Patient-Driven Groupings Model (PDGM): U.S. Department of Health and Human Services (HHS); 2019 [Available from: https://www.cms.gov/Outreach-and-Education/Outreach/NPC/Downloads/2019-02-12-PDGM-Presentation.pdf.

31. Centers of Medicare \& Medicaid Services. SNF PPS: Patient Driven Payment Model: U.S. Department of Health and Human Services (HHS); 2018 [Available from: https://www.cms.gov/Medicare/Medicare-Fee-for-Service-Payment/SNFPPS/Downloads/MLN_CalL_PDPM_Presentation_508.pdf.

32. Arksey H, O'Malley L. Scoping studies: towards a methodological framework. International Journal of Social Research Methodology. 2005;8(1):19-32.

33. Tricco AC, Lillie E, Zarin W, O'Brien KK, Colquhoun H, Levac D, et al. PRISMA Extension for Scoping Reviews (PRISMA-ScR): Checklist and Explanation. Annals of Internal Medicine. 2018;169(7):467-73.

34. Waltz TJ, Powell BJ, Matthieu MM, Damschroder LJ, Chinman MJ, Smith JL, et al. Use of concept mapping to characterize relationships among implementation strategies and assess their feasibility and importance: results from the Expert Recommendations for Implementing Change (ERIC) study. Implementation Science. 2015;10(1).

35. Powell BJ, McMillen JC, Proctor EK, Carpenter CR, Griffey RT, Bunger AC, et al. A compilation of strategies for implementing clinical innovations in health and mental health. Medical care research and review : MCRR. 2012;69(2):123-57.

36. Doyle SD, Bennett S. Feasibility and Effect of a Professional Education Workshop for Occupational Therapists' Management of Upper-Limb Poststroke Sensory Impairment. American Journal of Occupational Therapy. 2014;68(3):e74-e83.

37. Connell LA, McMahon NE, Watkins CL, Eng JJ. Therapists' use of the Graded Repetitive Arm Supplementary Program (GRASP) intervention: a practice implementation survey study. Phys Ther. 2014;94(5):632-43.

38. Frith J, Hubbard I, James C, Warren-Forward H. In the Driver's Seat: Development and Implementation of an e-Learning Module on Return-to-Driving After Stroke. Occupational Therapy in Health Care. 2017;31(2):150-61.

39. Braun SM, van Haastregt JC, Beurskens AJ, Gielen Al, Wade DT, Schols JM. Feasibility of a mental practice intervention in stroke patients in nursing homes; a process evaluation. BMC Neurology. 2010;10:9.

40. Eriksson C, Erikson A, Tham K, Guidetti S. Occupational therapists experiences of implementing a new complex intervention in collaboration with researchers: a qualitative longitudinal study. Scandinavian Journal of Occupational Therapy. 2017;24(2):116-25.

Page 9/21 
41. Levac DE, Glegg SM, Sveistrup H, Colquhoun H, Miller P, Finestone H, et al. Promoting Therapists' Use of Motor Learning Strategies within Virtual RealityBased Stroke Rehabilitation. PLoS One. 2016;11(12):e0168311.

42. McCluskey A, Ada L, Kelly PJ, Middleton S, Goodall S, Grimshaw JM, et al. A behavior change program to increase outings delivered during therapy to stroke survivors by community rehabilitation teams: The Out-and-About trial. Int J Stroke. 2016;11(4):425-37.

43. McEwen SE, Donald M, Jutzi K, Allen KA, Avery L, Dawson DR, et al. Implementing a function-based cognitive strategy intervention within interprofessional stroke rehabilitation teams: Changes in provider knowledge, self-efficacy and practice. PLoS One. 2019;14(3).

44. Moore JL, Carpenter J, Doyle AM, Doyle L, Hansen P, Hahn B, et al. Development, Implementation, and Use of a Process to Promote Knowledge Translation in Rehabilitation. Archives of Physical Medicine and Rehabilitation. 2018;99(1):82-90.

45. Petzold A, Korner-Bitensky N, Salbach NM, Ahmed S, Menon A, Ogourtsova T. Increasing knowledge of best practices for occupational therapists treating post-stroke unilateral spatial neglect: Results of a knowledge-translation intervention study. Journal of Rehabilitation Medicine. 2012;44(2):118-24.

46. Salbach NM, Wood-Dauphinee S, Desrosiers J, Eng JJ, Graham ID, Jaglal SB, et al. Facilitated interprofessional implementation of a physical rehabilitation guideline for stroke in inpatient settings: process evaluation of a cluster randomized trial. Implementation Science. 2017;12:1-11.

47. Vratsistas-Curto A, McCluskey A, Schurr K. Use of audit, feedback and education increased guideline implementation in a multidisciplinary stroke unit. BMJ Open Qual. 2017;6(2):e000212.

48. McCluskey A, Middleton S. Increasing delivery of an outdoor journey intervention to people with stroke: A feasibility study involving five community rehabilitation teams. Implement Sci. 2010;5:59.

49. McCluskey A, Massie L, Gibson G, Pinkerton L, Vandenberg A. Increasing the delivery of upper limb constraint-induced movement therapy post-stroke: A feasibility implementation study. Australian Occupational Therapy Journal. 2020.

50. McEwen S, Szurek K, Polatajko HJ, Rappolt S. Rehabilitation education program for stroke (REPS): learning and practice outcomes. J Contin Educ Health Prof. 2005;25(2):105-15.

51. Teriö M, Eriksson G, Kamwesiga JT, Guidetti S. What's in it for me? A process evaluation of the implementation of a mobile phone-supported intervention after stroke in Uganda. BMC Public Health. 2019;19(1):562.

52. Willems M, Schröder C, van der Weijden T, Post MW, Visser-Meily AM. Encouraging post-stroke patients to be active seems possible: results of an intervention study with knowledge brokers. Disabil Rehabil. 2016;38(17):1748-55.

53. Bland MD, Sturmoski A, Whitson M, Harris H, Connor LT, Fucetola R, et al. Clinician adherence to a standardized assessment battery across settings and disciplines in a poststroke rehabilitation population. Archives of Physical Medicine and Rehabilitation. 2013;94(6):1048-53.e1.

54. Clarke DJ, Godfrey M, Hawkins R, Sadler E, Harding G, Forster A, et al. Implementing a training intervention to support caregivers after stroke: a process evaluation examining the initiation and embedding of programme change. Implement Sci. 2013;8(1):96.

55. Kristensen $\mathrm{H}$, Hounsgaard L. Evaluating the impact of audits and feedback as methods for implementation of evidence in stroke rehabilitation. British Journal of Occupational Therapy. 2014;77(5):251-9.

56. Luconi F, Rochette A, Grad R, Hallé MC, Chin D, Habib B, et al. A multifaceted continuing professional development intervention to move stroke rehabilitation guidelines into professional practice: A feasibility study. Topics in Stroke Rehabilitation. 2020.

57. Schneider EJ, Lannin NA, Ada L. A professional development program increased the intensity of practice undertaken in an inpatient, upper limb rehabilitation class: A pre-post study. Aust Occup Ther J. 2019;66(3):362-8.

58. Stewart C, Power E, McCluskey A, Kuys S, Lovarini M. Evaluation of a staff behaviour change intervention to increase the use of ward-based practice books and active practice during inpatient stroke rehabilitation: a phase-1 pre-post observational study. Clinical Rehabilitation. 2020.

59. Tetteroo D, Timmermans AA, Seelen HA, Markopoulos P. TagTrainer: supporting exercise variability and tailoring in technology supported upper limb training. J Neuroeng Rehabil. 2014;11:140.

60. Connell LA, McMahon NE, Harris JE, Watkins CL, Eng JJ. A formative evaluation of the implementation of an upper limb stroke rehabilitation intervention in clinical practice: a qualitative interview study. Implement Sci. 2014;9:90.

61. Levac D, Glegg SM, Sveistrup H, Colquhoun H, Miller PA, Finestone H, et al. A knowledge translation intervention to enhance clinical application of a virtual reality system in stroke rehabilitation. BMC Health Serv Res. 2016;16(1):557.

62. Waltz TJ, Powell BJ, Fernández ME, Abadie B, Damschroder LJ. Choosing implementation strategies to address contextual barriers: diversity in recommendations and future directions. Implementation Science. 2019;14(1).

63. Elwy AR, Wasan AD, Gillman AG, Johnston KL, Dodds N, Mcfarland C, et al. Using formative evaluation methods to improve clinical implementation efforts: Description and an example. Psychiatry Research. 2020;283:112532.

64. Tetroe JM, Graham ID, Foy R, Robinson N, Eccles MP, Wensing M, et al. Health Research Funding Agencies' Support and Promotion of Knowledge Translation: An International Study. The Milbank Quarterly. 2008;86(1):125-55.

65. Lane JP, Flagg JL. Translating three states of knowledge-discovery, invention, and innovation. Implementation Science. 2010;5(1):9.

66. Nilsen P. Making sense of implementation theories, models and frameworks. Implementation Science. 2015;10(1):53.

67. Ridde V, Pérez D, Robert E. Using implementation science theories and frameworks in global health. BMJ Global Health. 2020;5(4):e002269.

68. Birken SA, Powell BJ, Shea CM, Haines ER, Alexis Kirk M, Leeman J, et al. Criteria for selecting implementation science theories and frameworks: results from an international survey. Implementation Science. 2017;12(1).

69. Levac D, Colquhoun H, O'Brien KK. Scoping studies: advancing the methodology. Implement Sci. 2010;5(1):69. 
70. Colquhoun HL, Levac D, O'Brien KK, Straus S, Tricco AC, Perrier L, et al. Scoping reviews: time for clarity in definition, methods, and reporting. Journal of Clinical Epidemiology. 2014;67(12):1291-4.

\section{Tables}

Table 1 Summary of characteristics, implementation clusters, discrete strategies \& outcomes of included studies 


\begin{tabular}{|c|c|c|c|c|c|c|c|c|c|c|c|}
\hline \multirow[t]{2}{*}{ Ref. } & \multirow[t]{2}{*}{ Year } & \multirow[t]{2}{*}{ Country } & \multirow{2}{*}{$\begin{array}{l}\text { Research } \\
\text { design }\end{array}$} & \multicolumn{8}{|c|}{ Strategy clusters a } \\
\hline & & & & $\begin{array}{l}\text { Use } \\
\text { evaluative } \\
\text { and } \\
\text { iterative } \\
\text { strategies }\end{array}$ & $\begin{array}{l}\text { Provide } \\
\text { interactive } \\
\text { assistance }\end{array}$ & $\begin{array}{l}\text { Adapt } \\
\text { and } \\
\text { tailor } \\
\text { to } \\
\text { context }\end{array}$ & $\begin{array}{l}\text { Develop } \\
\text { stakeholder } \\
\text { interrelationships }\end{array}$ & $\begin{array}{l}\text { Train and } \\
\text { educate } \\
\text { stakeholders }\end{array}$ & $\begin{array}{l}\text { Support } \\
\text { clinicians }\end{array}$ & $\begin{array}{l}\text { Engage } \\
\text { consumers }\end{array}$ & $\begin{array}{l}\text { Utilizє } \\
\text { financ } \\
\text { strate }\end{array}$ \\
\hline
\end{tabular}

Discrete implementation strategy ${ }^{b}$

$\begin{array}{llrr}\text { (50) } 2005 \text { Canada } & \text { Before/After } & 3354 & 57 \\ & & 2955\end{array}$

(39) 2010 Netherlands Mixed

methods

process

evaluation
1516

2955

(48) 2010 Australia Before/After 4

16

(45) 2012 Canada Before/After

63

$16192931 \quad 58$

43

$\begin{array}{lll}\text { (53) } 2013 & \begin{array}{l}\text { United } \\ \text { States }\end{array} & \begin{array}{l}\text { Cohort - } \\ \text { retrospective }\end{array} \\ & & 426\end{array}$

Page $12 / 21$ 


\begin{tabular}{|c|c|c|c|c|c|c|c|c|c|c|c|}
\hline \multirow[t]{2}{*}{ Ref. } & \multirow[t]{2}{*}{ Year } & \multirow[t]{2}{*}{ Country } & \multirow{2}{*}{$\begin{array}{l}\text { Research } \\
\text { design }\end{array}$} & \multicolumn{8}{|c|}{ Strategy clusters ${ }^{a}$} \\
\hline & & & & $\begin{array}{l}\text { Use } \\
\text { evaluative } \\
\text { and } \\
\text { iterative } \\
\text { strategies }\end{array}$ & $\begin{array}{l}\text { Provide } \\
\text { interactive } \\
\text { assistance }\end{array}$ & $\begin{array}{l}\text { Adapt } \\
\text { and } \\
\text { tailor } \\
\text { to } \\
\text { context }\end{array}$ & $\begin{array}{l}\text { Develop } \\
\text { stakeholder } \\
\text { interrelationships }\end{array}$ & $\begin{array}{l}\text { Train and } \\
\text { educate } \\
\text { stakeholders }\end{array}$ & $\begin{array}{l}\text { Support } \\
\text { clinicians }\end{array}$ & $\begin{array}{l}\text { Engage } \\
\text { consumers }\end{array}$ & $\begin{array}{l}\text { Utilizє } \\
\text { financ } \\
\text { strate }\end{array}$ \\
\hline (54) & 2013 & United & Process & 4 & & & & 1571 & & & \\
\hline
\end{tabular}

$(60)$

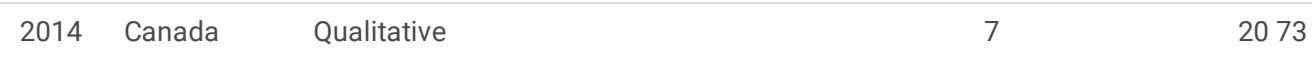

(37)

$2014 \quad \begin{array}{ll}\text { United } & \begin{array}{l}\text { Cross- } \\ \text { Kingdom } \\ \text { sectional }\end{array}\end{array}$

3672

(36)

$2014 \begin{aligned} & \text { United } \quad \text { Before/After } \\ & \text { States }\end{aligned}$

162931

$\begin{array}{lll}\text { (55) } 2014 \text { Denmark } & \begin{array}{l}\text { Cohort - } \\ \text { retrospective }\end{array}\end{array}$ 


\begin{tabular}{|c|c|c|c|c|c|c|c|c|c|c|c|}
\hline \multirow[t]{2}{*}{ Ref. } & \multirow[t]{2}{*}{ Year } & \multirow[t]{2}{*}{ Country } & \multirow{2}{*}{$\begin{array}{l}\text { Research } \\
\text { design }\end{array}$} & \multicolumn{8}{|c|}{ Strategy clusters ${ }^{a}$} \\
\hline & & & & $\begin{array}{l}\text { Use } \\
\text { evaluative } \\
\text { and } \\
\text { iterative } \\
\text { strategies }\end{array}$ & $\begin{array}{l}\text { Provide } \\
\text { interactive } \\
\text { assistance }\end{array}$ & $\begin{array}{l}\text { Adapt } \\
\text { and } \\
\text { tailor } \\
\text { to } \\
\text { context }\end{array}$ & $\begin{array}{l}\text { Develop } \\
\text { stakeholder } \\
\text { interrelationships }\end{array}$ & $\begin{array}{l}\text { Train and } \\
\text { educate } \\
\text { stakeholders }\end{array}$ & $\begin{array}{l}\text { Support } \\
\text { clinicians }\end{array}$ & $\begin{array}{l}\text { Engage } \\
\text { consumers }\end{array}$ & $\begin{array}{l}\text { Utilize } \\
\text { finane } \\
\text { strate }\end{array}$ \\
\hline (59) & 2014 & Netherlands & $\begin{array}{l}\text { Mixed } \\
\text { methods } \\
\text { process } \\
\text { evaluation }\end{array}$ & 56 & 54 & & & 15194355 & & & \\
\hline (61) & 2016 & Canada & Before/After & & & & 35 & 294355 & 58 & & \\
\hline (41) & 2016 & Canada & Before/After & & & & & 1631 & 58 & & \\
\hline (42) & 2016 & Australia & $\begin{array}{l}\text { Randomized } \\
\text { controlled } \\
\text { trial }\end{array}$ & $\begin{array}{l}4 \\
5\end{array}$ & & & & 1931 & & & \\
\hline (52) & 2016 & Netherlands & Before/After & 4661 & & 51 & 3857 & 71 & 58 & 4150 & \\
\hline
\end{tabular}




\begin{tabular}{|c|c|c|c|c|c|c|c|c|c|c|c|}
\hline \multirow[t]{2}{*}{ Ref. } & \multirow[t]{2}{*}{ Year } & \multirow[t]{2}{*}{ Country } & \multirow{2}{*}{$\begin{array}{l}\text { Research } \\
\text { design }\end{array}$} & \multicolumn{8}{|c|}{ Strategy clusters ${ }^{a}$} \\
\hline & & & & $\begin{array}{l}\text { Use } \\
\text { evaluative } \\
\text { and } \\
\text { iterative } \\
\text { strategies }\end{array}$ & $\begin{array}{l}\text { Provide } \\
\text { interactive } \\
\text { assistance }\end{array}$ & $\begin{array}{l}\text { Adapt } \\
\text { and } \\
\text { tailor } \\
\text { to } \\
\text { context }\end{array}$ & $\begin{array}{l}\text { Develop } \\
\text { stakeholder } \\
\text { interrelationships }\end{array}$ & $\begin{array}{l}\text { Train and } \\
\text { educate } \\
\text { stakeholders }\end{array}$ & $\begin{array}{l}\text { Support } \\
\text { clinicians }\end{array}$ & $\begin{array}{l}\text { Engage } \\
\text { consumers }\end{array}$ & $\begin{array}{l}\text { Utilize } \\
\text { financ } \\
\text { strate }\end{array}$ \\
\hline (40) & 2017 & Sweden & $\begin{array}{l}\text { Qualitative; } \\
\text { Before/After }\end{array}$ & 56 & 33 & 51 & 244748 & 20293143 & & & \\
\hline
\end{tabular}

(38) 2017 Australia Before/After

63

2931

30

$\begin{array}{lllllll}\text { (46) } 2017 & \text { Canada } & \begin{array}{l}\text { Process } \\ \text { evaluation }\end{array} & 4 & 33 & 735 & 162031\end{array}$

(47) 2017 Australia Before/After 4

\section{5}

14

United
States

Time series

55661

27

53

5163

5163
67

1724354064

19293155

71 


\begin{tabular}{|c|c|c|c|c|c|c|c|c|c|c|c|}
\hline \multirow[t]{2}{*}{ Ref. } & \multirow[t]{2}{*}{ Year } & \multirow[t]{2}{*}{ Country } & \multirow{2}{*}{$\begin{array}{l}\text { Research } \\
\text { design }\end{array}$} & \multicolumn{8}{|c|}{ Strategy clusters ${ }^{a}$} \\
\hline & & & & $\begin{array}{l}\text { Use } \\
\text { evaluative } \\
\text { and } \\
\text { iterative } \\
\text { strategies }\end{array}$ & $\begin{array}{l}\text { Provide } \\
\text { interactive } \\
\text { assistance }\end{array}$ & $\begin{array}{l}\text { Adapt } \\
\text { and } \\
\text { tailor } \\
\text { to } \\
\text { context }\end{array}$ & $\begin{array}{l}\text { Develop } \\
\text { stakeholder } \\
\text { interrelationships }\end{array}$ & $\begin{array}{l}\text { Train and } \\
\text { educate } \\
\text { stakeholders }\end{array}$ & $\begin{array}{l}\text { Support } \\
\text { clinicians }\end{array}$ & $\begin{array}{l}\text { Engage } \\
\text { consumers }\end{array}$ & $\begin{array}{l}\text { Utilize } \\
\text { financ } \\
\text { strate }\end{array}$ \\
\hline (43) & 2019 & Canada & Before/After & & 8 & & 3552 & 161931 & 58 & & \\
\hline
\end{tabular}

(57)

2019 Australia Before/After 423

(51) 2019 Uganda $\quad \begin{aligned} & \text { Case study } \\ & \text { process } \\ & \text { evaluation }\end{aligned} \quad 52356 \quad 3354 \quad 51 \quad 1619 \quad 41$

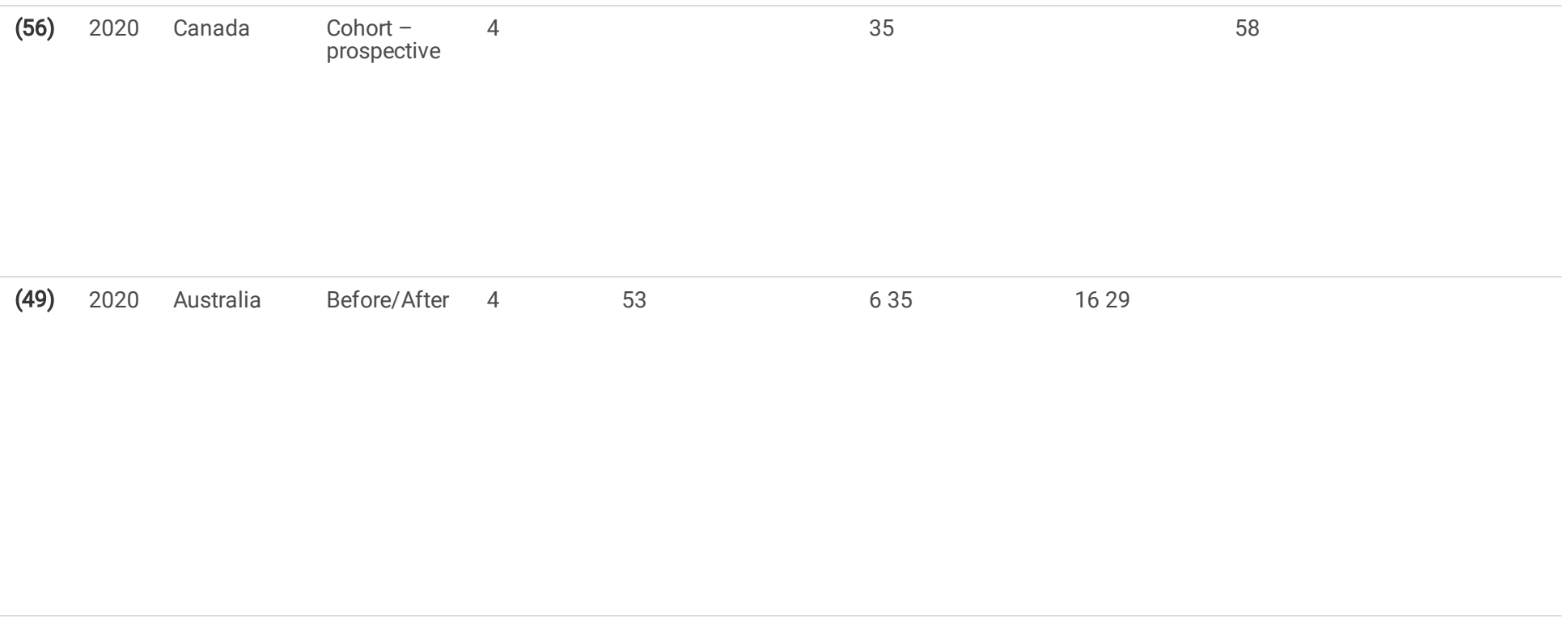




\begin{tabular}{|c|c|c|c|c|c|c|c|c|c|c|c|}
\hline \multirow[t]{2}{*}{ Ref. } & \multirow[t]{2}{*}{ Year } & \multirow[t]{2}{*}{ Country } & \multirow{2}{*}{$\begin{array}{l}\text { Research } \\
\text { design }\end{array}$} & \multicolumn{8}{|c|}{ Strategy clusters ${ }^{a}$} \\
\hline & & & & $\begin{array}{l}\text { Use } \\
\text { evaluative } \\
\text { and } \\
\text { iterative } \\
\text { strategies }\end{array}$ & $\begin{array}{l}\text { Provide } \\
\text { interactive } \\
\text { assistance }\end{array}$ & $\begin{array}{l}\text { Adapt } \\
\text { and } \\
\text { tailor } \\
\text { to } \\
\text { context }\end{array}$ & $\begin{array}{l}\text { Develop } \\
\text { stakeholder } \\
\text { interrelationships }\end{array}$ & $\begin{array}{l}\text { Train and } \\
\text { educate } \\
\text { stakeholders }\end{array}$ & $\begin{array}{l}\text { Support } \\
\text { clinicians }\end{array}$ & $\begin{array}{l}\text { Engage } \\
\text { consumers }\end{array}$ & $\begin{array}{l}\text { Utilizє } \\
\text { finane } \\
\text { strate }\end{array}$ \\
\hline \multirow[t]{2}{*}{ (58) } & \multirow[t]{2}{*}{2020} & \multirow[t]{2}{*}{ Australia } & \multirow{2}{*}{$\begin{array}{l}\text { Qualitative; } \\
\text { Before/After }\end{array}$} & 4 & & & & \multirow[t]{2}{*}{192055} & & & \\
\hline & & & & 5 & & & & & & & \\
\hline Total & & & & 17 & 8 & 6 & 12 & 23 & 8 & 2 & 1 \\
\hline
\end{tabular}

Adapted from ERIC discrete implementation strategy compilation (27), ERIC strategy clusters (34), and taxonomy of implementation outcomes (28).

a ERIC strategy clusters: Use evaluative and iterative strategies $(4,5,14,18,23,26,27,46,56,61)$, Provide interactive assistance $(8,33,53,54)$, Adapt and tailor to context $(51,63,67,68)$, Develop stakeholder interrelationships $(6,7,17,24,25,35,36,38,40,45,47,48,52,57,64,65,72)$, Train and educate stakeholders $(15,16,19,20,29,31,43,55,60,71,73)$, Support clinicians $(21,30,32,58,59)$, Engage consumers $(37,39,41,50,69)$, Utilize financial strategies $(1,2,3,28,34$, $42,49,66,70)$, and Change infrastructure $(9,10,11,12,13,22,44,62)$.

${ }^{\mathrm{b}}$ Numbering system matches the system used by Powell et al. (27) and Waltz et al. (34) in referencing discrete implementation strategies.

Table 2 Implementation frameworks used to guide and evaluate implementation process in studies. 


\begin{tabular}{|c|c|c|c|}
\hline Ref. & Year & Usage $(\mathrm{Y} / \mathrm{N})$ & Theoretical framework \\
\hline (50) & 2005 & No & $\mathrm{N} / \mathrm{A}$ \\
\hline (39) & 2010 & No & $\mathrm{N} / \mathrm{A}$ \\
\hline (48) & 2010 & No & $\mathrm{N} / \mathrm{A}$ \\
\hline (45) & 2012 & Yes & Knowledge-to-Action Model \\
\hline (53) & 2013 & No & $\mathrm{N} / \mathrm{A}$ \\
\hline (54) & 2013 & Yes & Normalization Process Theory \\
\hline (60) & 2014 & Yes & Normalization Process Theory \\
\hline (37) & 2014 & Yes & CFIR \\
\hline (36) & 2014 & Yes & Theory of Planned Behavior, Knowledge-to-Action framework, Adult Learning Theory \\
\hline (55) & 2014 & No & $\mathrm{N} / \mathrm{A}$ \\
\hline (59) & 2014 & No & $\mathrm{N} / \mathrm{A}$ \\
\hline (61) & 2016 & No & $\mathrm{N} / \mathrm{A}$ \\
\hline (41) & 2016 & No & $\mathrm{N} / \mathrm{A}$ \\
\hline (42) & 2016 & No & $\mathrm{N} / \mathrm{A}$ \\
\hline$(52)$ & 2016 & No & $\mathrm{N} / \mathrm{A}$ \\
\hline (40) & 2017 & No & $\mathrm{N} / \mathrm{A}$ \\
\hline (38) & 2017 & No & $\mathrm{N} / \mathrm{A}$ \\
\hline (46) & 2017 & Yes & Knowledge-to-Action framework \\
\hline (47) & 2017 & Yes & Theoretical Domains Framework; Behavior Change Wheel \\
\hline (44) & 2018 & Yes & Knowledge-to-Action framework \\
\hline (43) & 2019 & No & $\mathrm{N} / \mathrm{A}$ \\
\hline (57) & 2019 & No & $\mathrm{N} / \mathrm{A}$ \\
\hline (51) & 2019 & Yes & integrated-Promoting Action on Research Implementation in Health Services (i-PARIHS) framework \\
\hline (56) & 2020 & Yes & Knowledge-to-Action framework \\
\hline (49) & 2020 & Yes & Behavior Change Wheel \\
\hline (58) & 2020 & Yes & Behavior Change Wheel \\
\hline
\end{tabular}

\section{Figures}




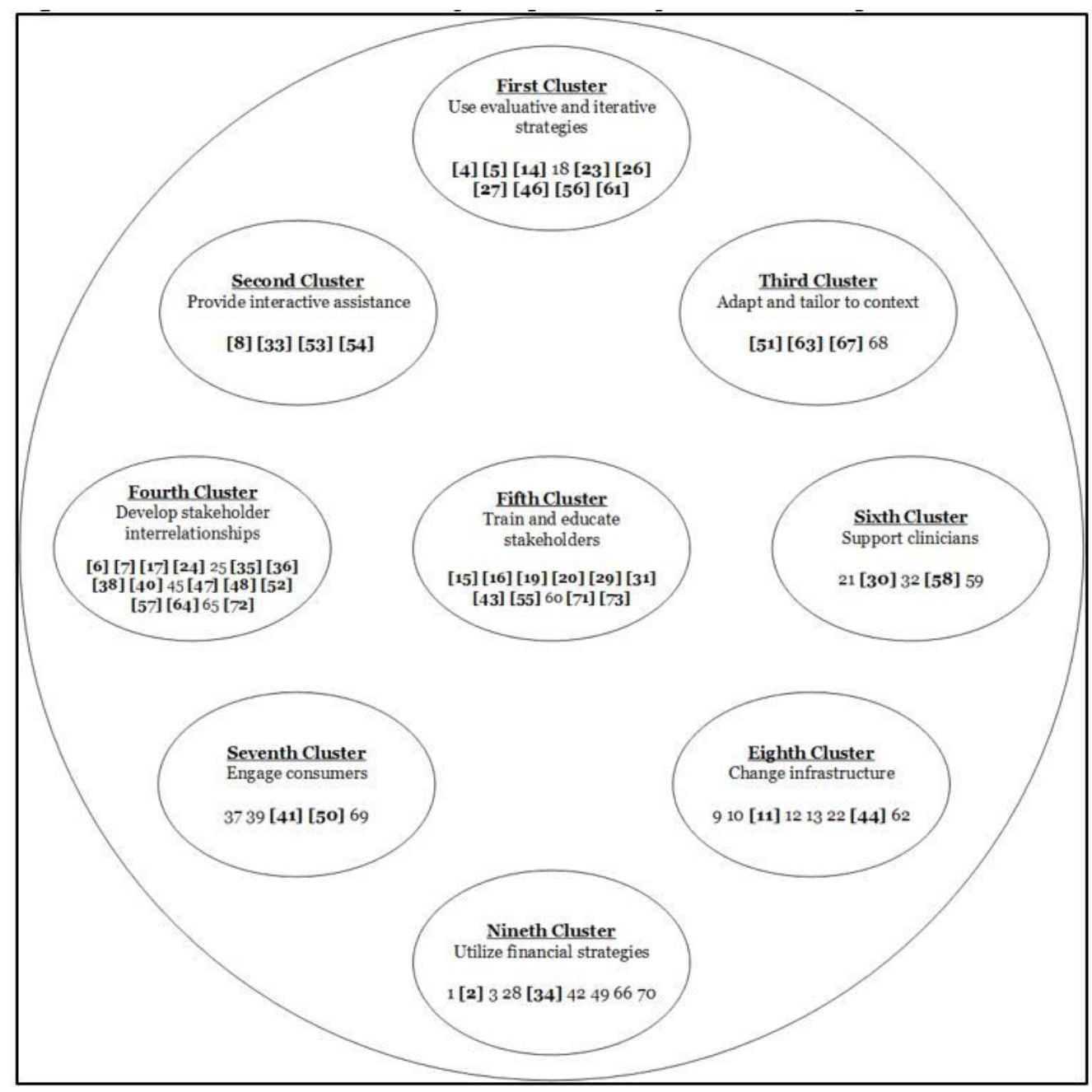

Figure 1

Nine thematic clusters and corresponding discrete implementation strategies 12 Adapted from the cluster map of all 73 strategies grouped by Waltz et al. (34). 1 The numbering system used matches the system by Powell et al. (27) and Waltz et al. (34) in referencing discrete implementation strategies. 2 [No.] listed in each cluster corresponding with the implementation strategies found in the scoping review studies. 


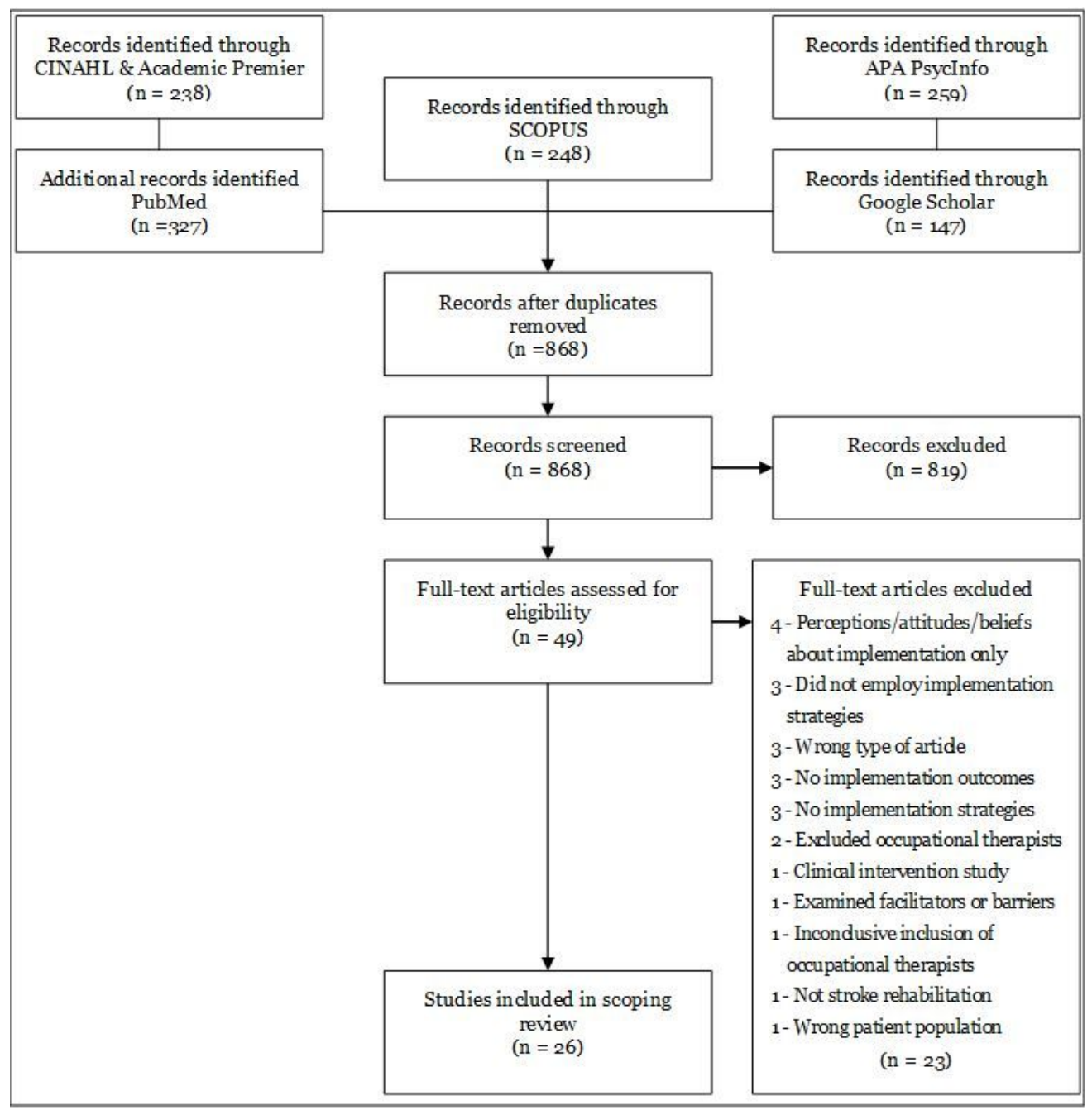

\section{Figure 2}

Study selection process adapted from The PRISMA Statement (32) 


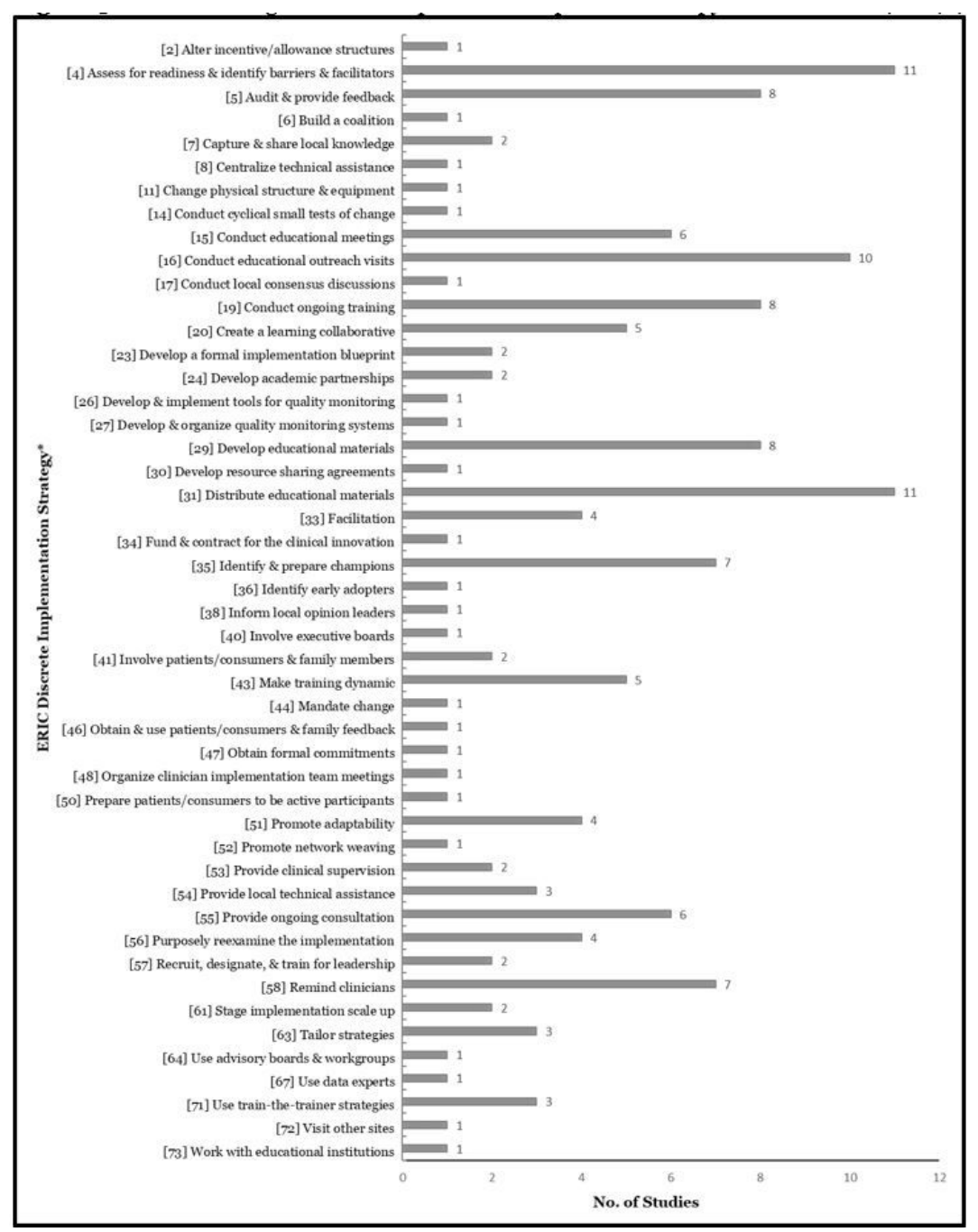

\section{Figure 3}

Discrete strategies used to implement occupational therapy EBP in studies ( $n=48)$ Adapted from ERIC discrete implementation strategy compilation (27). * [No.] matches the numbering system used by Powell et al. (27) and Waltz et al. (34) in referencing discrete implementation strategies.

\section{Supplementary Files}

This is a list of supplementary files associated with this preprint. Click to download.

- additionalfileone.docx 